SECTION 21. Pedagogy. Psychology. Innovations in the field of education.

\author{
Zinovyeva Tatyana Alexandrovna \\ $4^{\text {th }}$-year student, \\ Belgorod National Research University, \\ Russia \\ Gudakova Ekaterina Vyacheslavovna \\ $4^{\text {th }}$-year student, \\ Belgorod National Research University, \\ Russia
}

\title{
LINGUISTICS AND REGIONAL GEOGRAPHY- ONLY PROS FOR STUDIES.
}

Abstract: In this article we would like to show how important linguistics and regional geography is in the process of studies at school. In order to illuminate the positive impact of this aspect we have touched upon various age groups of pupils and the methods that would be more effective for full acceptance of this kind of material. The main aim of the text is to prove that such aspect as linguistics and regional geography plays a vital role in forming communicative competence of pupils.

Key words: linguistics and regional geography, communicative competence, process of studies, culture and values.

\section{ЛИНГВОСТРАНОВЕДЧЕСКИЙ АСПЕКТ КАК ПОЗИТИВНЫЙ ЭЛЕМЕНТ В ОБУЧЕНИИ.}

\begin{abstract}
Аннотация: В данной статье нам бы хотелось показать всю важность лингвострановедения для прочесса обучения в школе. Для этого мы затронули разные возрастные группы (начальный этап, среднее звено) и наиболее эффективные методы для восприятия материала лингвострановедческого характера. Главная цель статьи доказать, что данный аспект играет далеко не последнюю роль в формировании коммуникативной компетенщии учащихся.
\end{abstract}

Ключевые слова: лингвострановедение, коммуникативная компетенция, процесс обучения, культура и ценности.

По некоторым данным на сегодняшний день в мире насчитывается более 2000 национальностей, каждая из которых обладает своим уникальным набором традиций и устоев. Именно поэтому можно с уверенностью говорить о том, что на данном этапе развития наш мир является не просто многонациональным, а мультикультурным.

Именно такой аспект как лингвострановедение (ЛСА) помогает учащимся в изучении не только культуры страны изучаемого языка, но и самого языка в целом. К сожалению, сегодня в школах этому не уделяется должное внимание. Конечно, на уроках английского учитель вывешивает карту и все старательно заучивают «the British Isles are washed by the waters of...». Но достаточно ли знать лишь положение страны на карте и the name of the queen? Это лишь страноведение, а как же быть с лингво-?

ЛСА помогает не просто расширить кругозор учащихся - происходит непосредственное знакомство детей с Великобританией или США, с иной национальной культурой и её ценностями. Но, как известно, всё познаётся в сравнении. И лингвострановедческий подход способствует формирования страноведческой компетенции, пропуская зарубежную культуру сквозь призму собственной. 
Принято выделять два подхода к изучению культуры в процессе освоения иностранного языка: обществоведческий и филологический. Первый подход, по мнению Г.Д.Томахина, «основывается на дисциплине, традиционно связанной с изучением любого иностранного языка. Так, страноведению больше присущи признаки обществоведческого подхода, поскольку страноведение воспринимается больше как комплексная дисциплина. Что же касается лингвострановедения, то данная дисциплина воспринимается больше как элемент практических языковых занятий, способствующий формированию коммуникативной компетенции учащихся.

При работе с таким аспектом как лингвострановедение необходимо правильно отобрать языковой материал, а именно тот, что связан непосредственно с культурой страны изучаемого языка. Это тот самый национально-культурный, лингвострановедческий компонент, при отборе содержимого которого из всего обилия лингвострановедческого материала выделяют тот, что имеет определённую педагогическую ценность. Сюда можно включить безэквивалентные, фоновые, коннотативные лексические единицы, узуальные формы речи, а также невербальные языки жестов, мимики и повседневного (привычного) поведения.

Особое внимание стоит обратить на «национальные реалии», т.е. средства языка, в которых заключён дух, колорит страны (для Великобритании - Tower of London, sandwich, English tea; для США - White house, liberty, New York), на фоновую лексику, которая не всегда может иметь одно значение, предлагаемое академическими учебниками и словарями. Эти единицы выделяются главным образом «по обусловленной внутриязыковыми фактами контрастивности плана содержания иноязычных единиц по сравнению с единицами родного языка». [2,с.26]

Само понятию реалии трактуется двояко:

1) реалия - предмет, понятие, явление, характерное для теории культуры, быта, уклада народа, страны и не встречающееся у других народов;

2) реалия - слово, обозначающее предмет, явление; также словосочетание (обычно фразеологизм, пословица, поговорка, включающее такие слова).[3,с.301]

Реалии наиболее наглядно раскрывают близость языка и культуры. Зачастую появление новой реалии в общественной жизни ведёт к появлению новой языковой реалии. Главное отличие реалии от любой другой языковой единицы - это наличие чётко выраженного предметного содержания, связанного как с народом и страной, так и с определённым отрезком времени в истории этой страны.

В переводоведении и лингвострановедении реалия представляет собой особую единицу и зачастую вызывает немало трудностей при переводе на родной язык обучающегося. К примеру, существует такое выражение как lollipop man. И это вовсе не продавец сладостей - так называется человек, регулирующий движение транспорта возле школы; он держит в руке предупредительный знак, который по форме напоминает леденец. Данное понятие можно отнести к классу лингвострановедческих реалий, поскольку человек, которому не известны особенности, традиции и герои страны, будет испытывать затруднения в понимании носителя языка.

Определившись с выбором материала, следующая задача - правильно ввести его в ход урока. Но стоит помнить, что введение лингвострановедческого компонента в преподавание иностранного языка предполагает достаточный уровень владения языком у обучаемых. На начальном этапе обучения это сделать довольно сложно, так как учащиеся, в первую очередь должны приобрести базовые сведения о фонетике, грамматике и лексике языка. Безусловно, можно попытаться вводить элементы ЛСА в игровой форме при изучении лексики, которая даёт больше пространства для внедрения этого аспекта, чем фонетика и грамматика. Однако, на мой взгляд, наиболее подходящая платформа знаний для внедрения ЛСА сформирована у обучающихся 
среднего звена - они уже могут более осознанно подходить к истории и культуре, тогда как на начальном этапе изучения языка формирование лингвострановедческой компетенции происходило неосознанно, а большей частью благодаря возрасту, когда ребёнок был более восприимчивым к поглощению новой информации. Здесь могут помочь стишки (Robin Bobin), разнообразные детские игры, которые любит и английские школьники в том числе (Egg-and-spoon race).

При формировании лингвострановедческой компетенции следует чётко выделить те умения и навыки, которые будут приобретены учащимися в процессе изучения лингвострановедения:

- навыки и умения оперировать отобранным языковым материалом (фоновой и безэквивалентной лексики);

- умения употреблять формулы речевого этикета в различных ситуациях;

- навыки и умения играть в игры сверстников страны изучаемого языка;

- умение принимать участие в культурных мероприятиях, связанных с национальными праздниками и обычаями.

Усвоение содержания лингвострановедческого компонента в обучении английскому языку - это основное условие приобщения к культуре страны, язык которой изучается. В этом путь к осуществлению иноязычного диалога культур, обладающего большими возможностями для создания социокультурного контекста развития личности ученика, для приобщения его к общечеловеческим ценностям и осознания их приоритета.

Как было сказано ранее, при изучении иностранной культуры, человек невольно привлекает элементы своей, сравнивая и оценивая. И это не случайно, ведь именно так удастся понять, как происходит восприятие мира у представителя другой культуры. Таким образом грань «свой-чужой» если не исчезает, то хотя бы становится прозрачной, позволяя погрузиться в реалии страны изучаемого языка. Более того, в процессе внедрения ЛСА учащимся предоставляется возможность проявить свои творческие способности, определить форму проведения урока. Это и работа с контурной картой, и изучение символики страны (гербы, эмблемы), и знакомство с бытовыми особенностями жизни (рецепты, устройство праздников и т.д.).

Мы черпаем знания из книг и научных текстов. Вот почему следует очень внимательно подходить к выбору текстового материала к уроку. Он должен не только соответствовать уровню знаний учащихся, но и быть динамичным, современным и аутентичным. Что представляет из себя аутентичный текст? Это не всегда сложная, неадаптированная литература, и бояться её не нужно. Вспомним, с чего мы начинали учить наш родной язык - это были сказки про Курочку Рябу, детские произведения С.Маршака, Н.Носова. Язык в этих книгах прост и понятен, рассчитан на определённую аудиторию. То же самое касается и зарубежной литературы. Лингвострановедческий материал в учебниках по английскому воспринимается обучающимися с большим энтузиазмом, такие тексты влияют не только на повышения уровня знаний о стране изучаемого языка в целом, но и на духовный мир и сознание в целом. Включение правильно подобранных аутентичных книг в программу обучения иностранному языку не только избавит учащихся от страха перед языком, но и сделает его изучение интересным и расширяющим не только знания по конкретному предмету, но и общий кругозор.

С.Г. Тер-Минасова в своей работе «Язык и межкультурная коммуникация» определяет язык как зеркало и сокровищницу, в котором отражены и сохранены ценности традиции общества.[4,с.80] Введение лингвострановедческого компонента в изучение языка крайне важно не только потому что он способствует формированию мотивации к его изучению, что чрезвычайно необходимо, так как само иноязычное 
общение не подкреплено языковой средой, реальной и необходимой, но и по причине того, что ЛСА в большей степени помогает развитию у учащихся способности к межкультурному взаимодействию и непосредственному использованию языка как инструмента для этого взаимодействия.

\section{Литература:}

1. Великобритания: Пособие по страноведению для старших классов, гимназий и школ с углубленным изучением иностранного языка /Сост. Ю. Голицынский.СПб.:КАРО,2002.-480c.

2. Перкас С.В. Систематизация и закрепление страноведческого материала на уроке английского языка //ИЯШ.-1993.- №6.- с.26-28.

3. Словари в работе переводчика //Современные теории и методики обучения иностранным языкам/Под редакцией Л.М. Федоровой, Т.И. Рязанцевой,-М.,2004.c.294-304.

4. Тер-Минасова С. Г. Язык и межкультурная коммуникация: (Учеб. пособие) М.: Слово/Slovo, 2000. - 624 с. 